\title{
Is the National Health Service Corps the Answer? (for Placing Family Doctors in Underserved Areas)
}

\author{
Douglas B. Kamerow, MD, $M P H$
}

Paying for college and medical school is expensive in the United States, often leaving recent graduates with large educational loan debt. ${ }^{1}$ This can influence the specialty medical students choose and where they practice. Analyzing a survey of boardcertified family physicians who were 3 years out of residency, Nagaraj et $\mathrm{al}^{2}$ report in this issue of the Journal of the American Board of Family Medicine that about $30 \%$ of this group were participating in some type of loan repayment program that offered debt forgiveness.

Educational debts and the repayment programs that help relieve such debts offer an opportunity to direct physicians to practices in medically underserved areas. Nagaraj and colleagues ${ }^{2}$ found, however, that of the $30 \%$ of young family physicians participating in debt relief, more than half were in programs that do not have such policies: approximately a quarter of the doctors were in loan forgiveness programs directly from their hospital or employer, and almost another quarter were enrolled in the federal Public Service Loan Forgiveness (PSLF) program. ${ }^{2}$

Although the "public service" in PSLF's title sounds like a program that requires placement in an area of need, in fact, it requires only that recipients work for any public or nonprofit entity. As approximately $75 \%$ of US hospitals are nonprofit or public, it makes it relatively easy to qualify for such repayment. ${ }^{3}$ However, there are drawbacks to the PSLF program that make it less attractive: it is

From Robert Graham Center, Georgetown University Department of Family Medicine, Washington, DC (DBK) Funding: none.

Conflict of interest: none declared.

Corresponding author: Douglas B. Kamerow, MD, MPH, Robert Graham Center, 1133 Connecticut Avenue, NW, Washington, DC 20036 (E-mail: dkamerow@aafp.org).

\section{See Related Article on Page 501.}

administratively cumbersome (resulting in delays) and it requires 10 years of documented loan payments before it pays off the balance of the loan. Still, it is a popular program, if the data from these young family physicians are representative.

A different, more long-standing federal loan forgiveness program that does require service in an underserved area is the National Health Service Corps (NHSC). According Nagaraj et $\mathrm{al}^{3}$, however, only $13 \%$ of the young family physicians surveyed who participated in loan repayment relief are in the NHSC. It is worth examining this program in some detail.

Congress created the NHSC in 1970 to address shortages of primary care clinicians in many US geographic areas and to assist health professional students in paying for their long years of training. The NHSC has 4 programs. The first is a scholarship program that pays tuition, expenses, and a stipend to health professional students in return for a service commitment to practice in a designated health professional shortage area (HPSA) after completing training. The second is a federal loan repayment program for clinicians working in HPSAs. There is also a small loan repayment program for medical students who commit to serving at least 3 years in an HPSA. Finally, a state program cofunds similar loan repayments in many (but not all) states. ${ }^{4}$

Most NHSC awards/agreements go to loan repayment, which only requires 2 to 3 years of service before payment. In 2016 (the last year for which data are available), 5282 of the 6129 awards went to federal loan repayment programs and 634 went to state loan repayment agreements. Only 213 scholarships were active in that year. ${ }^{5}$

By some accounts, the NHSC has been very successful at attracting and retaining health professionals to underserved areas. Various studies have found that up to half of NHSC loan reimbursement and scholarship recipients remain in an 
HPSA 10 years after completing their commitment. ${ }^{5}$ My personal history matches that statistic: I began my US Public Health Service career as an NHSC scholarship recipient working in an HPSA in 1979. Although I was a "failure" to commit after my payback was completed, I am proud to note that my practice partner is still working as a family doctor at our NHSC site, 37 years after our obligations ended! 6

Although the NHSC has been successful in placing many primary care physicians in HPSAs, it is by no means staffed mainly by doctors. Most NHSC assignees are not physicians. In September 2016, only $21.3 \%$ of NHSC staff in the field were doctors. Another fifth were nurse practitioners and almost one-third were mental and behavioral health professionals. ${ }^{5}$

There is room in the NHSC for physician growth, however. Funding for the NHSC has held steady at around $\$ 300$ million in recent years, supporting about 9,000 to 10,000 assignees. But there are approximately $50 \%$ more unfilled slots for NHSC clinicians annually; in September 2017, for example, the NHSC had 4,596 open positions. ${ }^{5}$ Even if the NHSC were fully staffed, however, it would not erase the primary care physician shortage in all areas, although (at current rates), it could add 1000 or so more doctors.

Thus, the NHSC is a long-standing program that has proven successful in achieving greater cli- nician workforce distribution. It seems that the newer, less restrictive PSLF program is competing with the NHSC but not delivering clinicians to medically underserved areas. Nagaraj et $\mathrm{al}^{2}$ have a point when they suggest that policy changes might result in funneling more young family doctors with big debts to practice in underserved areas through the NHSC and its affiliated state loan payback programs. The trick, of course, is getting the budget increases necessary to support growth in these activities.

\section{References}

1. Bazemore A, Peterson L, Jetty A, Wingrove P, Petterson S, Phillips R. Over half of graduating family medicine residents report more than $\$ 150,000$ in educational debt. J Am Board Fam Med 2018;29: $180-1$.

2. Nagaraj M, Coffman M, Bazemore A. 30\% of recent family medicine graduates report participation in loan repayment programs. J Am Board Fam Med 2018;31:501-2.

3. Friedman AB, Grischkan JA, Dorsey ER, George BP. Forgiven but not relieved: US physician workforce consequences of changes to public service loan forgiveness. J Gen Intern Med 2016;31:1237-41.

4. The National Health Service Corps. Available from: https://nhsc.hrsa.gov.

5. Heisler EJ. The National Health Service Corps. Congressional Research Service Report R44970. March 9, 2018; Washington, DC. Available from: https://www. hsdl.org/?view\&did $=808853$.

6. Carolyn L. Mok, personal communication. 